\title{
The role of audiovisual arts in disaster risk perceptional education in children and adolescents
}

\section{Letter to editor}

Annually, disasters and emergencies cause many deaths among children and adolescents across the world. ${ }^{1,2}$ However, educating children and adolescents to prevent the disaster risks and improve their resilience can save many lives. ${ }^{3,4}$

Parents might have died in an effort to save their children. But if the children were familiar with escapist skills such as hiding in a safer place during earth quakes, the family members wouldn't have lost their lives. With high occurrences of hazards and adverse effects of disasters world over, the need for education and risk perception awareness, inevitably, is a major concern. The new Framework for Disaster Risk Reduction 2015-2030 document (SFDRR) proposes use of children's capacity in disaster risk alleviation programs to help children understand and respond to disasters and disaster preparedness. ${ }^{5}$ Children have the capacity to learn disaster risk reduction, disaster preparedness for themselves, prevent others and promote community resilience in general. ${ }^{6,7}$ Children can help families and community by transferring knowledge and lessons from the preparedness skills to reduce the level of risks. Not only in the preparatory phase, but response and recovery, the older children and adolescents can inform alert, and assist the community in psychosocial recovery, and preevent conditions in social resilience. ${ }^{8}$

Children resilience ${ }^{9}$ in disasters, is a notable, complex and challenging concept. ${ }^{10}$ in recent years .Internal and external components, including mental, emotional, spiritual, physical- social and behavioral skills are comprehensible indicators of planning ${ }^{3}$ while in the school as an environment, education plays significant role in developing resilience and training in disaster risks reduction. ${ }^{1}$

The high mental growth of children and adolescents on one hand and the development of technology, on the other show that teachercentered education cannot satisfactorily convey such complex concepts. But performing arts ${ }^{11}$ as a teaching technique can make the education procedure very smooth, attractive and achievable. However, use of audiovisual in collaboration with children and adolescents has greater impact in raising awareness.

Extensive studies on the culture and art of children and adolescents have shown that the advent and development of digital technology and media ${ }^{12,13}$ have failed to diminish the appeal of performing arts to children. However, reinforcement of the arts from a policy and infrastructure ${ }^{14}$ perspective should be considered for specialized training.

So, the nature of the visual and audiovisual arts is useful and effective for teaching and conveying complex concepts of disaster risk reduction for children and adolescents.

Whereas individual education and skills include internal components; psychological, emotional, cognitive, spiritual and physical- and external components including social and behavioral skills ${ }^{3,7,8}$ of child and adolescent resiliency. . In disaster, the use of art,
Volume 5 Issue 5 - 2020

\author{
Leila Mohammadinia,' Elham Mohammadinia² \\ 'PhD, Department of Health in Disasters and Emergencies, \\ Health and Human Resources Research Center, School of \\ Management and Information Sciences, Shiraz University of \\ Medical Sciences, Iran \\ ${ }^{2}$ M.Sc. Student in Art Research, University of Surah, Iran
}

Correspondence: Leila Mohammadinia, Ph.D. Department of Health in Disasters and Emergencies, Health and Human Resources Research Center, School of Management and Information Sciences, Shiraz University of Medical Sciences, Shiraz, Iran, Email Lela.mohammadinia@gmail.com

Received: February 18, 2020 | Published: October 12, 2020

especially audiovisual will be a turning point in promoting resilience for children and adolescents.

\section{Acknowledgments}

None.

\section{Conflicts of interest}

The authors declare no conflicts of interest.

\section{References}

1. Mirzaei S, Dehghani-Tafti AA, Mohammadinia L, et al. Operational strategies for establishing disaster-resilient schools: a qualitative study. Advanced Journal of Emergency Medicine. 2019:4(2).

2. Mohammadinia L, Ebadi A, Malekafzali H. Evaluation of the resilience of students in golestan and kermanshah provinces, Iran, against natural hazards. 2019;11(1):36-41.

3. Mohammadinia L, Khorasani-Zavareh D, Ebadi A, et al. Characteristics and components of children'sand adolescents' resilience in disasters in Iran: a qualitative study. International journal of qualitative studies on health and well-being. 2018;13(sup1):1479584.

4. Mohammadinia L. Children Co-operation in healthcare after disasters. Pall Car Nur. 2017;1(2):107.

5. Cumiskey L, Hoang T, Suzuki S, et al. Youth participation at the third UN world conference on disaster risk reduction. International Journal of Disaster Risk Science. 2015;6(2):150-163.

6. Mohammadinia L, Khorasani-Zavareh D, Ardalan A. Children capacity in disaster risk reduction: a call for action. Journal of injury and violence research. 2016;9(1):69-70.

7. Mohammadinia L, Ebadi A, Malekafzali H. Resilient children in natural disasters: LAP LAMBERT. Academic Publishing. 2018.

8. Mohammadinia L, Ardalan A, Khorasani-Zavareh D, et al. Domains and indicators of resilient children in natural disasters: A systematic literature review. International journal of preventive medicine. 2018;9. 
9. Theron L, Liebenberg L, Ungar M. Youth resilience and culture: Springer; 2015.

10. Mohammadinia L, Ebadi A, Malekafzali H, et al. The design and psychometric evaluation of the adolescents' resiliencein disaster tool (ARDT-Q37): A mixed method study. Heliyon. 2019;5(7):e02019.

11. Chemi T, Du X. Arts-based methods in education around the world: River Publishers; 2018.

12. Mourlam DJ, Strouse GA, Newland LA, Lin H. Can they do it? A comparison of teacher candidates' beliefs and preschoolers' actual skills with digital technology and media. Computers \& Education. 2019;129:82-91.
13. Fernandes GWR, Rodrigues AM, Ferreira CA. Conceptions of the nature of science and technology: a study with children andyouths in a nonformal science and technology education setting. Research in Science Education. 2018;48(5):1071-106.

14. Glick H. Arts for all: an analysis of arts access as it relates to socioeconomic status and other demographic factors (thesis). 2019. 